\title{
PARTICIPACIÓN POLÍTICA Y DEMOCRACIA REPRESENTATIVA
}

\section{PARTICIPAÇÃO POLÍTICA E DEMOCRACLA REPRESENTATIVA José Adrián García Rojas ${ }^{2}$}

\footnotetext{
Recebido em: 17/01/2019

Aceito em: 18/01/2019

andreaugusto.gf@gmail.com
}

El título que propongo para esta conferencia no es nada original, pero, precisamente por eso, ya nos ofrece una idea clara de lo que voy a exponerles a continuación. Efectivamente, no se entiende la democracia sin participación ni representación. La adjetivemos de la forma que queramos, bien sea como burguesa frente a la auténtica democracia del socialismo real, que era la democracia popular, o tildándola de orgánica, como definía el régimen del General Franco a su régimen autoritario, o bien manejemos el usual de término de democracia liberal frente al de democracia social, que se unen, en mi opinión en la concepción del Estado Social y Democrático de Derecho. Podemos colegir que no existe régimen alguno que prevea ciertas formas o cauces -en expresión del régimen franquista- de participación y de representación política. La primera puede ser más o menos propiciada desde el Estado. Puede contar con más o menos impedimentos, permitir o no partidos políticos, ser un régimen que ponga el acento en los derechos civiles y políticos y en las libertades fundamentales o hacerlo, como en los regímenes comunistas o de socialismo real, en los derechos colectivos y sociales. También en todos los regímenes políticos, sean autoritarios o democráticos liberales, nos encontramos con cámaras o asambleas representativas de tipo corporativo, como en los sistemas autoritarios y fascistas, populares y pretendidamente asamblearios, a la manera de los soviets, o en la tradicional y liberal forma de un Parlamento. Tanta ha sido la discusión doctrinal sobre lo que es la democracia, que el politólogo norteamericano Robert A. DAHL propuso denominar a las democracias liberales con el nombre de "poliarquías".

El concepto de representación es un concepto que nos es familiar en nuestra vida cotidiana y que se utiliza en un sentido político y no político en variadas situaciones y formas, como inicia en su conocida obra sobre el tema de la representación el profesor A.H. BIRCH. La noción de participación política implica, en opinión del profesor FERRANDO BADÍA:

1. La pertenencia a una comunidad política.

2. El concepto de ciudadano.

3. La idea de un poder político.

\footnotetext{
${ }^{1}$ Conferencia inaugural del Congreso Internacional sobre Problemas actuales de la cultura jurídica en el contexto global, organizado por el Departamento de Derecho Constitucional, Ciencia Política y Filosofía del Derecho de la Universidad de La Laguna y celebrado en la Facultad de Derecho de la Universidad de La Laguna los días 17 y 18 de diciembre de 2018.

${ }^{2}$ Universidade de La Laguna - ULL - Santa Cruz de Tenerife - Espanha
} 
Toda persona pertenece o es miembro de una sociedad y como miembro de esa sociedad participa en su vida política de una u otra forma. Una comunidad política se caracteriza por estar formada por diversos individuos y grupos de todo tipo. Pero, de igual forma, toda comunidad se ordena y estructura social, económica y políticamente. Estructurar y ordenar una sociedad políticamente significa, como nos recuerda DUCLOS (citado por FERRANDO BADÍA), "alterar mediante un aparato social determinado el curso espontáneo de las relaciones sociales con el propósito de dar continuidad a una cierta forma de cohesión social". El aparato del Estado, como dejó escrito MAX WEBER, puede, en última instancia, utilizar legítimamente su monopolio en el uso de la fuerza para asegurar la cohesión y supervivencia de la sociedad.

La democracia, y su correlato de extensión del sufragio, conlleva la idea de ampliación de la participación política, como observó el profesor MURILLO FERROL, y lleva, asimismo, implícita la idea de que más hombres se conviertan en ciudadanos, es decir, en personas portadoras del derecho de participar políticamente. La participación existe en todos los regímenes políticos. En regímenes democráticos y en regímenes autocráticos, pero reviste formas distintas en unos y en otros, como nos recuerda DUVERGER. En los regímenes autoritarios excluyen a la ciudadanía de la elección de sus gobernantes y no favorecen las libertades ciudadanas ni la participación política espontánea, que es lo contrario de lo que se sucede en las democracias. Estas ideas nos llevan a la definición de ciudadano, que, como señalamos anteriormente, está implícita en la noción de participación democrática. Ciudadano es la persona que reúne las condiciones necesarias para participar en los asuntos públicos. La idea de ciudadano, por tanto, se opone a la de súbdito, que sería la que encontramos en los regímenes autoritarios y totalitarios tanto a la derecha como a la izquierda del espectro político. En ambos casos, ciudadano y súbdito, tienen una cosa en común: son hombres insertos en una comunidad política.

Sabemos desde la Revolución francesa que una cosa son los derechos del hombre y otra los derechos de los hombres que, además tienen la condición de ciudadanos. Los ciudadanos tienen los derechos inherentes a su condición de hombres y aquellos de los que les dotan la Constitución y las leyes. En este sentido, los primeros artículos de la Declaración de Derechos del Hombre y del Ciudadano (1789) se refieren al hombre. Así, el artículo $1^{\circ}$ declara que "Los hombres nacen y permanecen libres e iguales en derechos. Las distinciones sociales sólo pueden fundarse en la utilidad común", y el $2^{\circ}$ manifiesta que "La finalidad de cualquier asociación política es la protección de los derechos naturales e imprescriptibles del Hombre" y prosigue en el mismo artículo señalando cuales son esos derechos naturales e imprescriptibles del hombre: "Tales derechos son la libertad, la propiedad, la seguridad y la resistencia a la opresión". A partir del artículo $3^{\circ}$, que es cuando se habla de que "toda Soberanía reside esencialmente en la Nación. Ningún cuerpo ni ningún individuo pueden ejercer autoridad alguna que no emane expresamente de ella", es cuando se comienza a hablar de los derechos de los ciudadanos, en mi opinión diferentes a los de los individuos en cuanto hombres. Así, dice textualmente el artículo $6^{\circ}$ que "La Ley es la expresión de la voluntad general. Todos los Ciudadanos tienen derecho a contribuir a su elaboración, personalmente o a través de sus Representantes. Debe ser la misma para todos, tanto para proteger como para sancionar. Además, puesto que todos los Ciudadanos son iguales ante la Ley, todos ellos pueden presentarse y ser 
elegidos para cualquier dignidad, cargo o empleo públicos, según sus capacidades y sin otra distinción que la de sus virtudes y aptitudes". A partir del artículo $7^{\circ}$, vuelve a hablar de derechos del hombre y se refiere también a los del ciudadano como hombre activo. A este respecto el artículo 11ํㅜ es ciertamente revelador, pues dice que "La libre comunicación de pensamientos y opiniones es uno de los derechos más valiosos del Hombre"; es decir que la libertad de pensar y expresar opiniones es de todo hombre, pero llevarla a cabo, comunicar esas opiniones y pensamientos o imprimirlas pertenece a ese hombre activo, al ciudadano. De esta forma termina el citado artículo $11^{\circ}$ señalando que "por consiguiente, cualquier Ciudadano puede hablar, escribir e imprimir libremente, siempre y cuando responda del abuso de esta libertad en los casos determinados por la Ley".

Un Estado es democrático si en su organización política prevalece el principio democrático y es autoritario si prevalece el principio autocrático, como nos enseñó KELSEN. Las instituciones distintivas del gobierno democrático, por lo menos como se entiende y concibe en los países occidentales, como nos advierte RAPHAEL, están destinadas a asegurar un máximo de libertad para los individuos que son ciudadanos de esos países con sistemas de democracia liberal. La idea de democracia va unida a la idea de libertad sin sujeción a nada ni a nadie, es decir, a la idea del buen salvaje o de Robinson Crusoe. Pero vivir en sociedad implica orden y el orden supone limitar la libertad. De ahí, que los contractualistas pensaran que el hombre sólo podía ser libre fuera del Estado, o, lo que es lo mismo, viviendo en lo que denominaban estado de naturaleza. CHÂTELET, DUHAMEL y PISIER-KOUCHNER dicen que fue Hugo GROCIO el autor que propuso la idea de que la sociedad política es producto y efecto de la sociabilidad del hombre y, por tanto, es una realización de la ley de la naturaleza. Será mediante contrato como sus miembros decidan voluntariamente, pues son libres en ese estado de naturaleza, someter la voluntad pública a una instancia soberana y perpetua, cuya misión es asegurar la paz y la concordia. La idea de hombres libres en estado de naturaleza tuvo perspectivas distintas, que podríamos fijar desde la visión pesimista de HOBBES hasta la más optimista de ROUSSEAU. El pensamiento de HOBBES parte de la base de que los hombres en estado de naturaleza carecen de "sociabilidad bondadosa", como apuntan los profesores franceses antes citados, que experimentan sentimientos entre los que predominan la envidia y el miedo, sobre todo al sufrimiento y la muerte. HOBBES expuso, desde su visión de la intranquila y desasosegante Gran Bretaña de su tiempo, su conocida idea de que el hombre en estado de naturaleza es un lobo para el hombre, por lo que su visión del hombre en estado de naturaleza es contradictoria, pues goza de plena libertad y de un miedo constante, "al margen de toda norma jurídica", como señalan CHÂTELET, DUHAMEL y PISIER-KOUCHNER. Los hombres por eso toman libremente la decisión de crear un artefacto, el Estado, al que someten su libertad con el propósito de vivir en paz. Ese Estado debe tener un poder sin límites, toda vez que, en su renuncia individual a su poder político, ese poder lo transfieren al Estado. En el otro extremo situamos a ROUSSEAU, cuyo primitivismo romántico, piensa ALF ROSS, lo lleva a su “adoración del hombre primitivo incorrupto" y su fe en el buen sentido del pueblo, que, en buena medida, procede de su imagen idealizada de su país natal, del que habla como el pueblo más feliz de la tierra. Para él, el hombre en estado de naturaleza no tiene instinto de ser sociable, pues, como escribió, "todo parece alejar del hombre salvaje la tentación de dejar de serlo". El cambio de la vida de este hombre libre y salvaje en estado 
de naturaleza, que para él es una ficción para explicar el surgimiento de la sociedad y el Estado, se debe a distintos accidentes por los que la sociedad cambia de naturaleza. "Desde el instante que un hombre tuvo necesidad de ayuda de otro, del momento que se dio cuenta que era útil para uno tener las provisiones de dos, desapareció la igualdad". Amenazados en su seguridad, apuntan los profesores CHÂTELET, DUHAMEL y PISIER-KOUCHNER, los hombres necesitan un determinado grado de organización política y llegar a concertar un contrato social. Ese es el fundamento del Estado en ROUSSEAU: una comunidad basada en un contrato social que garantiza, en su opinión, la desigualdad entre los hombres.

KELSEN pensaba con acierto que la libertad natural se convierte en un sistema democrático en libertad política. Por ello, en libertad con restricciones. La libertad en el Estado democrático lo es en relación a una serie de vínculos. La libertad política es y significa autonomía del individuo. La libertad política, por ello, está constreñida por varios principios, entre otros, los de:

1. Mayoría.

2. Igualdad.

3. Respeto a la minoría.

La democracia se nutre de la discusión y de la aceptación de intereses y opiniones distintas y contrapuestas. De la discusión entre mayoría y minoría nace el compromiso. La participación política se lleva a cabo, en democracia, a través de la democracia directa y de la democracia indirecta o representativa. La diferenciación en las condiciones sociales conduce a la división del trabajo en la economía, pero también en la creación del Derecho. Los ciudadanos transfieren a través de su voto su función de gobierno, que poseen por su condición de soberanos, a unos representantes. A ello se refería KELSEN cuando hablaba de "la ficción de la representación" en su obra Teoría General del Derecho y del Estado. La idea de representación supuso una rectificación de la democracia, en palabras de SÁNCHEZ AGESTA, pues entre representante y representado hay una dualidad de voluntades de las que, inevitablemente, surgen diferencias.

Cuando con la Revolución Francesa la burguesía logró una representación paritaria a la de los estamentos privilegiados del Antiguo Régimen, lo consigue en base a determinados principios políticos, como los de:

1. Soberanía nacional frente al de Monarquía absoluta.

2. Mandato representativo frente a mandato imperativo.

El profesor de Derecho Constitucional Antonio TORRES DEL MORAL resume y sintetiza en tres las teorías de la representación. Dos son producto de procesos históricos y doctrinarios claramente diferentes, mientras que el tercero es fruto del pensamiento jurídico. Así, podemos clasificarlas en:

A) La teoría anglosajona de la confianza que se fue desarrollando históricamente desde la Edad Media en el Reino Unido. Esta teoría o idea de la representación partía de la base de que no se sabía cómo iría el curso de las negociaciones entre los representantes mandatarios sobre diferentes asuntos, fundamentalmente de tipo presupuestario, así como al hecho de que los representantes no podían reunirse constantemente con sus representados ni recibir mandatos en función de dichas negociaciones. Todo ello hizo que los mandatos comenzaran 
a ser muy genéricos y que, de hecho, se obviaran, pues el Monarca inglés exigía que los representantes llevaran amplios poderes para avanzar en las negociaciones. Como se puede observar, esta teoría es deudora del conocido pragmatismo británico. El Agreement of the People (1653) partía de esa idea del trust (confianza) entre representantes y representados. En el ámbito teórico son reseñables las aportaciones a este tema de la representación en la obra Consideraciones sobre el Gobierno representativo de John LOCKE y en el Discurso a los electores de Bristol (1774) de Edmund BURKE. En el primero se resalta que, idealmente, la mejor forma de gobierno es el gobierno representativo, en el que el voto de los representantes, obtenido gracias a su inclusión en la Constitución o por la costumbre, se desliga de la opinión de los electores. Pero, como observa A.H. BIRCH, las ideas de LOCKE sobre la representación están lejos de ser claras, aunque su importante no se deba a su claridad sino a su originaliad. Añadiría yo a lo expuesto, que LOCKE fue muy original en su reflexión sobre este tema de la representación en el momento histórico en que vivió, como también lo fueron sus propuestas sobre el gobierno por consentimiento y el papel de la mayoría. BURKE, tan cabalmente estudiado por MACPHERSON, llegó a la misma conclusión que sus combatidos constituyentes revolucionarios franceses, pues, pese a ser el más fiero enemigo de la Revolución, como subraya SARTORI, llegó a su misma conclusión: la de que los representantes no deben ser mandatarios, pues deben representar a la nación y no a sus mandatarios. Recordemos que, en su ya citado discurso enviado, en 1774, a los electores de Bristol, les decía que el Parlamento no "es un congreso de embajadores con intereses opuestos y hostiles; (...) es, por el contrario, una asamblea deliberante de una nación, con un único interés, el del conjunto; donde no deberían existir como guía objetivos y prejuicios locales sino el bien general (...). En efecto, vosotros elegís a un miembro, pero cuando lo habéis elegido, no es un miembro de Bristol, sino un miembro del Parlamento". Por eso, como dice PITKIN, dado que la relación de cada parlamentario es con la nación como un todo, no mantiene el representante ninguna relación especial con sus electores, pues representa a la nación, pero no a aquellos que lo eligieron.

B) La teoría francesa del mandato representativo, que nace antes de la Revolución, pero que ya está en El Espíritu de las Leyes de Montesquieu, cuando se refiere a los mandatos generales de los representados o mandatarios para dar libertad a los representantes en los Estados Generales. CONDORECET y SIEYÈS coinciden con esta visión del mandato. No así Rousseau, que era contrario a esta forma de representación. Decía CONDORCET que "el pueblo me ha enviado no para sustraer sus opiniones sino para exponer las mías". SYEYĖS abogaba por que los representantes del estado llano fueran elegidos por los ciudadanos pertenecientes a este estamento. Y explicaba quién pertenecía a dicho sector social en su condición de "no estar tachado de ninguna clase de privilegio". Su segunda petición es la igualdad en el número de diputados a los de los otros dos estamentos de las clases privilegiadas. La tercera petición también es bien conocida, "que los Estados generales voten, no por clases, sino por cabezas". Posición contraria y radical a las dos anteriores es la de ROUSSEAU, quien afirma que "la soberanía no puede ser representada, por la misma razón 
que no puede ser enajenada; consiste esencialmente en la voluntad general, y la voluntad no se representa; o es ella misma, o es otra: no hay término medio". De ahí que los diputados no son ni pueden ser sus representantes, sólo sus delegados. No pueden concluir nada sin el acuerdo de sus mandatarios y, por tanto, toda ley que el pueblo en persona no haya ratificado es nula. La Declaración de Derechos del Hombre y del Ciudadano (1789) recogió las ideas de CONDORCET y SIEYÈS, entre otros, al señalar que:

1. La ley es expresión de la voluntad general, de la soberanía nacional, que es una indivisible.

2. Esta unidad e indivisibilidad exige que los representantes lo sean de la Nación y no de electores concretos.

3. La Nación no puede querer ni actuar por sí misma sino sólo a través de representes, lo que implicaba la prohibición del mandato imperativo.

4. La Constitución es representativa.

C) La teoría del órgano, elaborada por JELLINEK, que niega la dualidad entre representante y representado, ya que sólo hay una sola voluntad, pues la de uno vale por la del otro. El representante es el órgano del representado, del pueblo. El pueblo como persona jurídica pública no puede expresar su voluntad sino a través de su órgano, como ocurre en el Derecho privado con las personas jurídicas.

La representación como artilugio de la ingeniería política y constitucional es un descubrimiento, como nos recuerda LOEWENSTEIN, equivalente a la invención de la máquina de vapor o a la electricidad, pues es un procedimiento que ha permitido mayor influencia popular sobre el poder político que en otros momentos históricos, además de convertirse en un instrumento para legitimar dicho poder y hacerlo responsable ante la ciudadanía. En el siglo Veinte se pasó de la democracia liberal individualista a una democracia pluralista, en la que el protagonista no es el hombre sino que son hombres que pertenecen, a su vez, a grupos. BURDEAU alertaba de que la representación política es un correctivo a la democracia, por lo que, para cumplir con su función legitimadora del sistema político, debía reforzarse la participación política. SABAINE opinaba que en su obra Sobre la libertad John STUART MILL hacía una defensa de la libertad en contra de la democracia. Los adjetivos democrático y antidemocrático, escribe RAPHAEL, se refieren al predominio o a la existencia de impedimentos o cortapisas a la libertad. Democracia va unido a libertad e igualdad de los hombres que viven en una comunidad política, que, en la actualidad, dada su enorme número de habitantes hace imposible el ejercicio directo de su función de gobierno en cuanto soberano en el sentido que le da a este término ROUSSEAU. Por tanto, no se entiende la democracia sin representación, pese a que, como señalamos anteriormente, sea un correctivo de la democracia en sentido estricto.

Las democracias liberales son representativas, pero eso no les niega que sean democracias. Como nos recuerda DAHL, democracia se relaciona con procesos por medio de los cuales los ciudadanos ejercen un cierto grado de control sobre sus dirigentes políticos y, añado yo, los diputados elegidos por ellos cada cierto número de años para que elijan, a su vez, al Gobierno, en las formas de gobierno parlamentarias, o directamente a sus Jefes de Estado o Presidentes de la 
República, en las presidenciales. DHAL parte de esta definición mínima de democracia, lo mismo que cuando habla de los requisitos de las democracias contemporáneas a las que él prefiere llamar poliarquías. Por tanto, los sistemas democráticos y representativos tienen que dar mayor protagonismo a sus ciudadanos, a las mayorías y a las minorías, a los que se sienten excluidos, a los que tienen opiniones diferentes. En esta línea, Norberto BOBBIO propuso reforzar la representatividad del sistema político democrático para que fuera más representativo de las clases sociales, las generaciones y las personas. El propuso reforzar:

1. El derecho de la minoría a tener puestos de representación política.

2. Favorecer a colectivos representados, como ocurre con las mujeres.

3. Descentralizar el poder para acercarlo a los ciudadanos.

En definitiva, había que hacer del Gobierno representativo un Gobierno responsable ante los ciudadanos. Fijémonos en los términos que utiliza el maestro italiano: reforzar la representatividad y acercar el poder a través de una descentralización del Estado y de la toma de decisiones que afectan a los ciudadanos. Todo ello nos conduce a un tema central de las democracias contemporáneas: el de democracia representativa y responsable y la cuestión del Estado de partidos. En la actualidad, los Parlamentos reflejan mejor la opinión popular que en otros momentos históricos, en el que el sufragio era censitario o capacitario e, incluso, en los primeros cuarenta años del siglo veinte cuando, salvo excepciones, se excluía a la mujer de ese derecho de voto. Hoy, los Parlamentos han dejado de ser el centro decisivo de la vida política, convirtiéndose, de hecho, en instituciones fundamentalmente representativas y de control político del Gobierno, pues el núcleo de las más importantes decisiones políticas es Poder Ejecutivo y, en buena medida también, la Administración Pública. Como observa TORRES DEL MORAL, el Parlamento fue cediendo paulatinamente terreno y el juego político se fue desplazando a otro sitio. En política los espacios se cubren rápidamente. El Parlamento cedió su lugar en el escenario político y ese protagonismo lo tomó paulatinamente el Poder Ejecutivo.

Los partidos políticos y sus cúpulas cumplen hoy la función de mediación entre los ciudadanos y el Estado que formalmente asigna la Constitución a los Parlamentos. Los partidos políticos son los que reclutan y seleccionan a los candidatos a diputados y senadores, a concejales y a cualquier aspirante a un cargo de representación; pero son, además, los que reciben los votos de los ciudadanos y los encargados de negociar entre sí para llegar a un acuerdo de Gobierno si ello fuera necesario al no disponer ningún partido político de la mayoría suficiente para gobernar. La disciplina política se impone a los diputados y senadores dentro de su grupo parlamentario en apoyo de las decisiones gubernamentales o en contra de ellas. La idea de "Estado de partidos" surge, como nos recuerda GARCÍA PELAYO, durante la República de Weimar en el período de entreguerras (1918-1939). Muchos autores se inclinaron, como sucedería en el período posterior a la Segunda Guerra Mundial, a constitucionalizar los partidos políticos. KELSEN fue partidario de esta idea. Y THOMA, como señala GARCíA PELAYO, pensaba que sólo el potencial organizativo de los partidos podía evitar la inestabilidad política derivada de los vaivenes emocionales que la puedan hacer caer en el desamparo, la desintegración y la demagogia.

Se trata de que la autoridad esté en manos de los que tengan la confianza de la mayoría y no en la de una minoría. Por eso, el Estado de partidos democrático se opone al Estado de clase o a un 
Estado oligárquico de los privilegiados. La democracia de partidos, nos vuelve a recordar GARCíA PELAYO, es una adaptación del principio democrático a las coyunturas históricas y a dos factores que están conectados entre sí:

1. La masificación del ejercicio de los derechos democráticos debido a la ampliación del derecho de sufragio y al aumento demográfico de las modernas democracias.

2. La sociedad actual es una sociedad organizacional.

Por ello, los diputados han perdido su genuino carácter de representantes. Esa es la razón de que en las elecciones el pueblo otorgue su confianza durante una legislatura al partido como organización y no a los diputados salidos de sus listas electorales, salvo en caso de los candidatos a la presidencia del Gobierno en sistemas parlamentarios de predominio del Ejecutivo o sistemas de canciller, que son los casos de la República Federal de Alemania y de España.

La democracia directa se ha convertido en las democracias contemporáneas en un complemento de la democracia representativa. Suiza institucionalizó el uso de diversos institutos de democracia directa, primero, en el ámbito de la comuna y el cantón y después en el nivel federal. Francia durante el bonapartismo utilizó la democracia directa como un arma del autoritarismo de Napoleón III. Tampoco el movimiento obrero fue unánime en su defensa o en su ataque a la democracia directa. En Alemania el Partido Social-Demócrata (PSD) fue favorable a las instituciones de democracia directa, pero uno de los ideólogos de esta doctrina política, Karl Kautsky, fue reticente a esta idea. Tras la Primera Guerra Mundial se volvió a plantear en el constitucionalismo de entreguerras su uso y su constitucionalización. Así se recogió en la Constitución austriaca y en la de Weimar. En España, la Constitución de la II República (1931), heredera en buena medida de esas dos Constituciones, la integró con restricciones para su utilización. CARRÉ DE MALBERG escribió a favor de estos institutos de democracia directa y de su necesaria convivencia con la democracia representativa. Otra idea favorable a la democracia directa lo fue como una forma de frenar el parlamentarismo exacerbado de este período entre las dos guerras mundiales, al que se achacaba la crisis económica, social y política que derivaría en el surgimiento de los totalitarismos en Alemania e Italia y en regímenes autoritarios en España, Portugal y otros países europeos.

Los regímenes autoritarios los incluyeron entre sus normas de carácter superior y cúspides de sus sistemas legales como una forma de legitimación de unos sistemas autoritarios y no representativos, aunque el balance de su utilización, por ejemplo, en España durante el régimen de Franco fue escaso. Sólo se utilizó dos veces en los cuarenta años que duró el régimen: en 1947 y 1966. No deja de ser curioso que la Ley para la Reforma Política, que fue propuesta por el Gobierno de Adolfo Suárez y ratificada por los representantes en las Cortes franquistas, fuera aprobada en referéndum por los españoles de forma mayoritaria. $Y$ es curioso porque fue, en buena medida, la última Ley Fundamental del régimen de Franco, elaborada por el segundo Gobierno de la naciente Monarquía del Rey Juan Carlos de Borbón, que desde la legalidad del régimen de Franco y con la aprobación de sus últimas Cortes de carácter corporativo, que no democrático ni electivo, sería el instrumento legal con que llevaría del viejo al nuevo régimen democrático a través de las primeras elecciones fundacionales del nuevo sistema político democrático español en junio de 1977. Régimen 
democrático que se dotó de la vigente Constitución de 1978, votada por todos los españoles el 6 de diciembre de 1978.

La V República incluyó el referéndum en su Constitución de 1958. Este deseo del hacedor del vigente régimen político francés, es parte de la particular concepción institucional y política del General De Gaulle. Esta idea la esbozó en su conocido discurso de Bayeux antes de que fuera rechazada su forma de ver la vida política francesa por los constituyentes que forjarían la IV República. Este rechazo de la clase política de la IV República a un régimen como el que surgiría en 1958, abocó al General DE Gaulle a su dimisión como primer ministro del Gobierno francés. Su retiro duró hasta que el fracaso del sistema de la IV República lo reclamó de nuevo para salvar el Estado francés en unos momentos de crisis política general derivada de los conflictos coloniales de Indochina y Argel. Su concepción de un Jefe del Estado con poderes reforzados y sin partido, que estuviese por encima de los vaivenes del juego político, tenía en el referéndum un lugar de encuentro directo del presidente con el pueblo francés. Esta visión se completó con la elección directa del Jefe del Estado y en su elección indefinida cada siete años. Para Raymond ARON, las originalidades de la V República, en relación a las democracias occidentales, son dos: la autoridad casi exclusiva del Presidente de la República en política exterior y defensa y la decadencia del parlamentarismo en favor de los burócratas y ministros, por un lado, y de los grupos de presión y profesionales, por otro. De Gaulle y su sucesor gaullista, el Presidente y antiguo Primer Ministro Pompidou, lo utilizaron seis veces en los catorce años iniciales del régimen al que DUVERGER bautizó con el apelativo de semipresidencialista.

VERGOTTINI clasifica los instrumentos de democracia directa en:

1. El derecho de petición, que es la facultad de solicitar medidas a los órganos constitucionales. Se puede utilizar individual o colectivamente para que los órganos constitucionales realicen determinadas actividades o tomen determinadas medidas. No obliga este derecho a la actuación solicitada por los ciudadanos. Más bien, los ciudadanos con este derecho de petición instan a los poderes públicos para que actúen.

2. El referéndum, que en España puede ser de varios tipos, como el de reforma constitucional, que puede ser obligatorio o a solicitud de un número determinado de diputados en función del calado que sea dicha reforma. También cabe el de ratificación de la iniciativa autonómica por la denominada vía del artículo 151 constitucional, o de una reforma estatutaria para la Comunidades Autónomas que accedieron por esa misma vía del 151, y también sobre decisiones políticas de carácter no legislativo de especial trascendencia.

3. El plebiscito, que se diferenciaría, en opinión de este autor, en que no se basa en decisiones legislativas sino en decisiones políticas, que, eso sí, posteriormente pueden plasmarse en leyes.

4. La iniciativa popular, que en España necesita quinientas mil firmas y que equivale a una iniciativa legislativa popular de presentación de una proposición de ley en el Congreso de los Diputados.

5. La revocación, que es un instituto de democracia directa, común en algunos estados y municipios norteamericanos, y que consiste en que un número determinados de electores 
puedan acabar con el mandato de un cargo público electo antes de éste finalice. No deja de ser curioso que en España se regulase su posible utilización en el régimen local en el Estatuto municipal elaborado durante la dictadura del General Primo de Rivera en los años veinte del pasado siglo veinte, que nunca entró en vigor.

Por último, haré unas breves reflexiones finales sobre democracia representativa y participación política en la España actual:

1. La Constitución española apunta con timidez líneas de ampliación de la democracia ciudadana en determinados ámbitos, como en la Administración de justicia, con la instauración del jurado, en la enseñanza, en las empresas, en la seguridad social y en otros ámbitos, en opinión del profesor MOLAS.

2. El artículo 23.1 de la Constitución española manifiesta que los ciudadanos tienen el derecho de participar en los asuntos públicos directamente o a través de representantes libremente elegidos. Como señala el profesor ÁLVAREZ CONDE, la Constitución española diseña un sistema de participación política de los ciudadanos en el que priman los mecanismos de democracia representativa sobre los de democracia directa. La fuente de legitimación del sistema político español y el instrumento de participación por excelencia es el de la democracia representativa.

3. Esta unanimidad doctrinal se vio confirmada por la Sentencia del Tribunal Constitucional (STC) 103/2008, de 11 de diciembre, que manifestó este carácter accesorio de los instrumentos de democracia directa en nuestro sistema político.

4. Como observa EXPÓSITO, frente a la visión "política" de la participación recogida en el artículo 23 de la Constitución, como derecho fundamental de la ciudadanía "a participar en los asuntos públicos", a la que ya nos hemos referido anteriormente, existe otro conjunto de previsiones que integrarían lo que conocemos como "democracia participativa" mediante el artículo 9.2 que apela a los poderes públicos a "facilitar la participación de todos los ciudadanos en la vida política, económica, cultural y social.

5. En línea con lo anterior, la Ley $7 / 1985$, de 2 de abril, reguladora de las bases del régimen local (LBRL), identifica a los municipios como los "cauces inmediatos de participación ciudadana en los asuntos públicos" en su artículo 1. La Ley 57/2003, de 16 de diciembre, de medidas para la modernización del gobierno local, profundiza en este sentido al insertar en la legislación local española determinados preceptos de la Recomendación del Comité de Ministros del Consejo de Europa, de 2001, que tratan sobre la participación ciudadana en la vida pública local, que fueron posteriormente integrados en los reglamentos de participación ciudadana municipales. Este hecho produjo, en opinión de FONT, una eclosión de la oferta de instrumentos de participación en el ámbito local, pese a que la demanda de aquellos a los que va dirigida esta oferta -los ciudadanos- no la hayan demandado en la misma medida.

6. Pese a todo, es en este ámbito, el del mundo de los gobiernos locales, donde estos instrumentos deben practicarse en mayor medida, en nuestra opinión. No sólo en lo que concierne al voto o la petición de determinadas actuaciones de la Administración local, insular o provincial, sino también en el de las Comunidades Autónomas, que jubilosamente han 
elaborado y aprobado leyes de participación ciudadana que impliquen a los ciudadanos en una participación más activa en la consulta sobre determinadas medidas como paso previo para su aprobación por los órganos habilitados para tal cometido.

\section{BIBLIOGRÁFÍA CITADA}

ÁLVAREZ CONDE, Enrique. Derecho Constitucional. Madrid: Tecnos, 2017.

ARON, Raymond. Ensayo sobre las libertades. Madrid: Alianza, 1984.

BIRCH, A.H. Representation. Londres: Pall mall Press. 1971.

BOBBIO, Norberto. La Teoría de las formas de gobierno en la Historia del Pensamiento Político. México DF: Fondo de Cultura Económica, 1987.

. Liberalismo y Democracia. México DF: Fondo de Cultura Económica, 1992.

BRUGUÉ, Quim. "Los ritmos y los tumbos de la participación ciudadana”. Cuadernos de la Fundación Manuel Giménez Abad, núm. 16, 2018.

CARRÉ DE MALBERG, Raymond. Teoría General del Estado. México DF: Fondo de Cultura Económica, 1998.

CHÂTELET, François; DUHAMEL, Olivier; PISIER-KOUCHNER, Evelyne, Historia del Pensamiento Político. Madrid: Tecnos, 1987.

DAHL, Robert A. Un prefacio a la Teoría Democrática. Buenos Aires: Grupo Editor Latinoamericano, 1989.

DUVERGER, Maurice. Instituciones Políticas y Derecho Constitucional. Barcelona: Ariel, 1970.

EXPÓSITO, Enriqueta: “Participación ciudadana en el gobierno local. Un análisis desde la perspectiva normativa", en Revista Aragonesa de Administración Pública, núm. XIV, 2013.

FERRANDO BADÍA, Juan. Estructura interna de la Constitución. Su dinámica política y factores. Valencia: Tirant lo Blanch, 1990.

FONT, Joan (editor). Ciudadanos y Decisiones Públicas. Barcelona: Ariel, 2001.

GARCÍA PELAYO, Manuel. Las transformaciones del Estado Contemporáneo. Madrid: Alianza, 1981.

El Estado de Partidos. Madrid: Alianza, 1986.

HOBBES, Thomas. Leviatán. Madrid: Alianza, 2018.

JELLINEK, Georg. Teoría General del Estado. México DF: Fondo de Cultura Económica, 2000.

KELSEN, Hans. Teoría general del Derecho y del Estado. México DF: Universidad Nacional Autónoma de México, 1988.

LOEWENSTEIN, Karl, Teoría de la Constitución. Barcelona: Ariel, 2018.

MACPHERSON, C.B. Burke. Madrid: Alianza, 1987.

MOLAS, Isidre. Derecho Constitucional. Madrid: Tecnos, 2008.

MURILLO FERROL, Francisco. Estudios de Sociología Política. Madrid: Tecnos, 1963.

Revista do Direito [ISSN 1982-9957]. Santa Cruz do Sul, v. 3, n. 56, p. 150-161, set/dez. 2018. https://online.unisc.br/seer/index.php/direito/index 
PITKIN, Hanna Fenichel. El concepto de representación. Madrid: Centro de Estudios Constitucionales, 1985.

RAPHAEL, D.D. Problemas de Filosofía Política. Madrid: Alianza, 1989.

ROSS, Alf. ¿Por qué democracia?. Madrid: Centro de Estudios Constitucionales, 1989.

ROUSSEAU, Jean-Jacques. Del Contrato Social. Sobre las Ciencias y las Artes. Sobre el Origen y los Fundamentos de la Desigualdad entre los Hombres. Madrid: Alianza, 1988.

SABINE, George H. Historia de la teoría política. México DF: Fondo de Cultura Económica, 2006.

SÁNCHEZ AGESTA, Luis. Principios de Teoría Política. Madrid: Editora Nacional, 1983.

SARTOI, Giovanni. Elementos de Teoría Política. Madrid: Alianza, 2005.

¿Qué es la democracia?. Madrid: Taurus, 2007.

SIEYÈS, Emmanuel-J. ¿Qué es el Estado llano?. Precedido del Ensayo sobre los privilegios. Madrid: Centro de Estudios Constitucionales, 1988.

STUART MILL, John. Consideraciones sobre el Gobierno Representativo. Madrid: Alianza, 2001.

TORRES DEL MORAL, Antonio. Estado de Derecho y Democracia de Partidos. Servicio de Publicaciones de la Facultad de Derecho. Madrid: Universidad Complutense, 1991.

1987. ; otros. Derecho Político, vol. 1, Madrid: Universidad Nacional de Educación a Distancia,

VERGOTTINI, Giuseppe. Derecho Constitucional Comparado. Madrid: Espasa-Calpe, 1985.

WEBER, Max. El político y el científico. Madrid: Alianza Editorial, 2012.

\section{COMO CITAR ESSE DOCUMENTO:}

GARCÍA ROJAS, José Adrián. Participación política y democracia representativa. Revista do Direito, Santa Cruz do Sul, v. 3, n. 56, jan. 2019. ISSN 1982-9957. Disponível em: <https://online.unisc.br/seer/index.php/direito/article/view/13069>. Acesso em: doi:https://doi.org/10.17058/rdunisc.v3i56.13069. 